Proceedings

\title{
Rooting. Peri-urban agroecology through territory planning
}

María del Mar Cobo ${ }^{1}$

${ }^{1}$ Universidad Politécnica de Madrid (UPM), E.T.S. de Arquitectura, Av. Juan de Herrera, 4, 28040 Madrid

* Correspondence: mar.cobo@icloud.com; Tel.: +36 683382339.

\begin{abstract}
The research is based on the fragility of the food system in urban environments. The increased demand for quality and healthy food, linked to sustainable production and consumption processes, is favouring the proliferation of agro-food strategies in proximity applied in territorial planning. This paper analyses three case studies of Spanish cities that have pioneered the incorporation of agro-ecological systems in peri-urban areas of cities as a tool for urban planning. The different planning strategies are compared with the guidelines proposed by the Sustainable Development Goals. The comparative analysis provides information about the benefits of incorporating organic food production at the local level and its approach to achieving more sustainable and selfsufficient cities.
\end{abstract}

Keywords: agroecology; food sovereignty; proximity agriculture; self-sufficient food systems; short distribution channels.

\section{Introduction}

In the context of climate change, environmental crises, loss of diversity and pandemic situations, cities and particularly vulnerable urban environments are being affected with consequences for social and environmental health, making the right to food more fragile.

[1] (p.3) In this context, the criticism of certain groups and social movements across a broad spectrum, and of academic sectors against massive urbanisation and its correlate of socio-economic crisis and fracture and environmental deterioration, in particular of the state and management of peri-urban open spaces, together with the growing demand for better quality food, rooted in place, and fairer from the perspective of consumption and production, is materialising in the formulation of a series of urban agri-food agendas and strategies.

In this paper, three case studies are selected. These are the Huerta de Valencia, the Metropolitan Area of Barcelona and the Aramangelu agro-ecological park in Vitoria. These are three planning strategies in each of the cities, which, among other tools, propose agroecological food production in peri-urban areas.

\section{Objectives and methodology}

The methodology consists of analysing the three case studies through the information in their management plans. A comparison of their proposals will then be made in relation to a series of variables. These are the guidelines proposed and followed in accordance with the 2030 Agenda to achieve the Sustainable Development Goals. The approach of the different proposals of the case studies to the achievement of the different Goals will be assessed from the point of view of agroecology and the territory.

The objective is to qualitatively demonstrate the benefits of incorporating local agrifood systems in order to build more sustainable and self-sufficient cities. It also aims to provide theoretical and practical information through these case studies in order to take them as a reference for the application of this type of measures in cities, after a search for their adaptation to each environment.

Agroecology and food sovereignty 
An adequate definition of the term "agroecology" states:

[2] (p.15) Agroecology is consolidated as a scientific approach to the extent that this field of knowledge is nourished by other scientific disciplines, as well as by the knowledge, know-how and experiences of the farmers themselves, which allows for the establishment of conceptual, methodological, and strategic frameworks with greater capacity to guide both the design and management of sustainable agroecosystems and the processes of sustainable rural development.

The second concept, "food sovereignty", was the subject of international agrarian debate in 1996 in Rome, where the World Food Summit was held, and was defined by Via Campesina as follows:

[3] The right of each people and all peoples to define their own policies and techniques of food production, distribution, and consumption in order to ensure culturally and nutritionally appropriate and sufficient food for the entire population.

\section{Case studies}

Huerta de Valencia

The Huerta of Valencia used to make up the agricultural matrix, nowadays it is the mixed urban-agricultural matrix, a free space where the metropolitan area of Valencia is settled and developed. This area has a population of one and a half million inhabitants and there are forty municipalities in it. Therefore, it is as space that has been undergoing a series of transformations in response to different urban planning interests.

The strategy of the Territorial Action Plan for the Huerta de Valencia (PAT) is a system for the protection of high-value spaces and a comprehensive territorial strategy, as well as the protection of other heritage, ecological, historical, scenic, productive, and recreational resources. The aim is to guarantee the preservation of the Huerta while promoting sustainable urban and economic development, to improve the quality of life of the inhabitants of the metropolitan area of Valencia.

Within the System of Open Spaces, called "Green Infrastructure", are all the valuable spaces and the elements that connect them in a functional way as a territorial or ecological strip, and which therefore allow an ecological, physical, and functional continuity in the territory of the Huerta. [4] [5] Information for the case study.

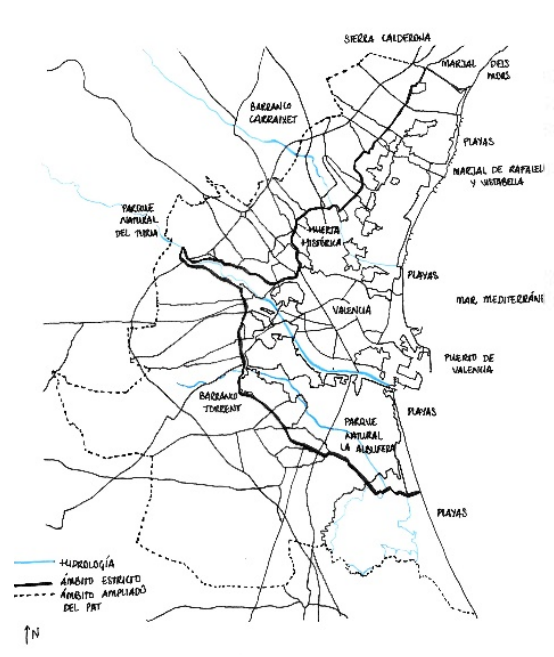

Figure 1. Ecologically valuable landscapes at Huerta de Valencia.

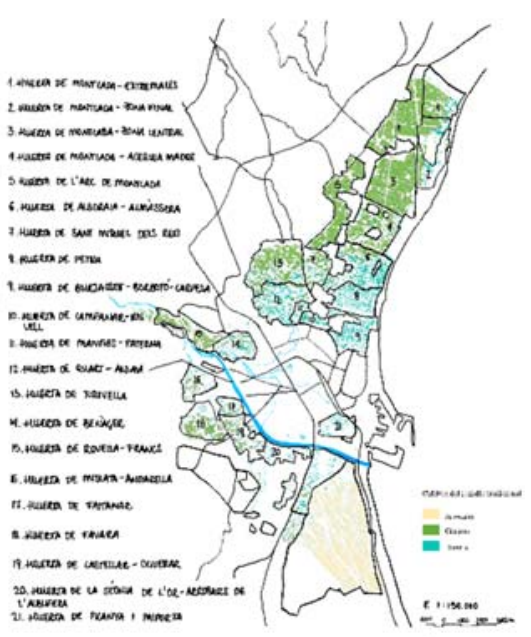

J*

Figure 2. Orchard varieties

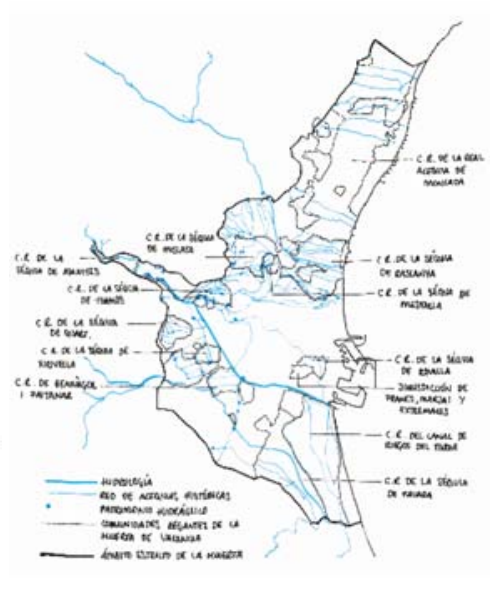

Figure 3. Historic irrigation network 
Metropolitan Area of Barcelona

The Área Metropolitana de Barcelona (AMB) is the current public administration of the territory of the metropolitan area of Barcelona. This territory includes 36 municipalities, 3,200,000 people and an extension of some 63,600 Ha.

In the metropolitan context, there were two main conflicts. On the one hand, fragmentation in the territory due to urban occupation and high-capacity infrastructures. This fragmentation previously threatened the functionality of ecosystems and agricultural systems. On the other hand, the loss of agricultural land due to this occupation. In the last 60 years, more than $80 \%$ of agricultural land has been lost due to two processes: one of them is the occupation by the city of the most fertile agricultural areas of the metropolitan area and, the other one is the abandonment of agricultural activity in the mountainous areas, where it is more difficult to farm.

Regarding the food system, the Plan establishes three guidelines, which have to do with three different scales, three different strategies.

- Protection - Agricultural areas.

- Reconnection through the metropolitan structure of urban settlements with their natural environment.

- Habitability and sustainability of the urban fabric.

[6] Information for the case study.

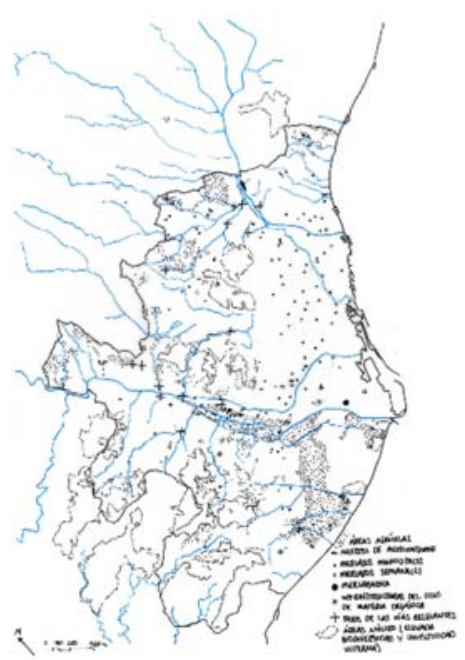

Figure 4. Agroforestry mosaic

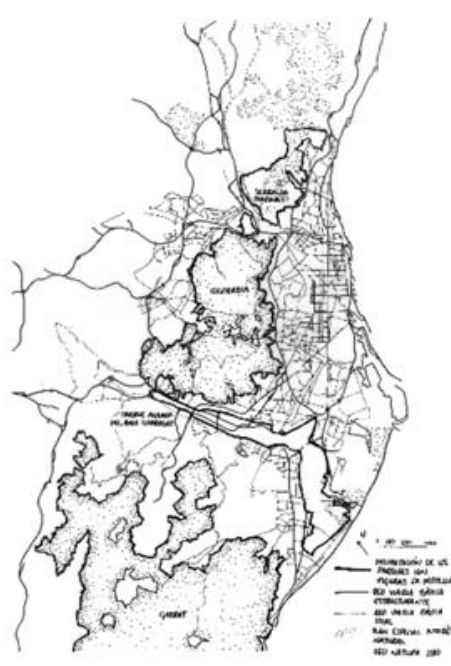

Figure 5. Structuring network and parks

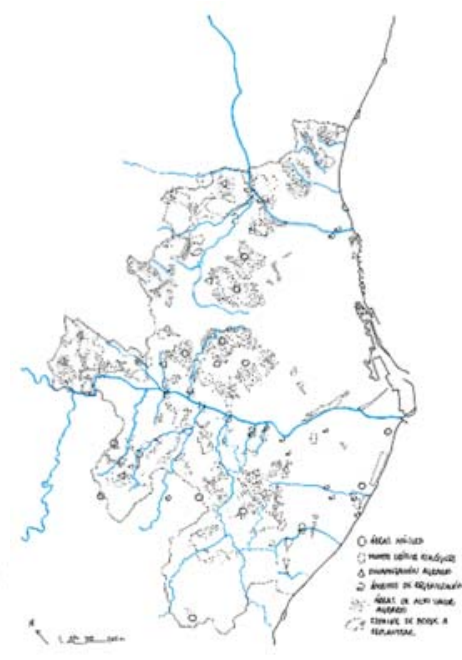

Figure 6. Local crops and markets

\section{Aramangelu agro-ecological park in Vitoria-Gasteiz}

Vitoria-Gasteiz is a city that "has always grown under some kind of planning". This has led to an evolution of the city from the planning point of view that is closely linked to Agenda 21, which has a good quality of life and was awarded in 2012 as European Green Capital.

[7] Specifically, in the municipality of Vitoria-Gasteiz, a functional ecological relationship is established between the mountains, the intermediate agricultural zone (with a predominance of crops, including some island forests, hedgerows and gallery forests, which includes sixty-four small rural nuclei). This is linked to the city bordered by the Green Belt (core elements) and connected to interior green spaces (nodes) through the planned network of strategic connectors.

The proposal for the Aramengelu Park arose as the union of several projects that were taking place in the northern area of the Agricultural Belt and is integrated into this as a space for agro-ecological food production in proximity. 


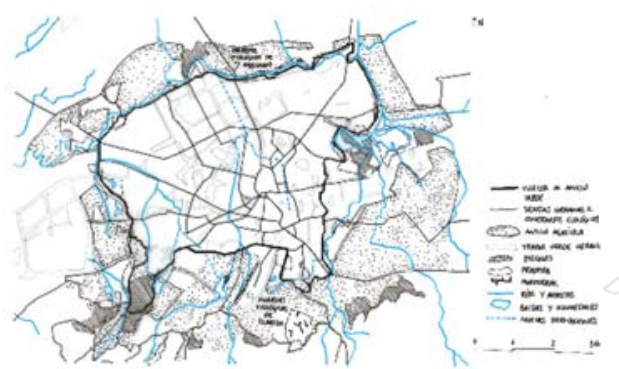

Figure 7. Agricultural belt

$<$

\section{Conclusions}

The incorporation of spaces for agroecological production in the three case studies, from the point of view of agroecology and territory, would comply with the guidelines proposed by SDG 11 Sustainable cities and communities and SDG 12 Responsible production and consumption. These systems are less harmful to the environment, reduce production and supply chains, and raise awareness of the consumption of local products. Alongside these, SDG 3 Health and well-being, due to the higher quality of the food produced.

Regarding SDG 13 Climate action and SDG 15 Life of terrestrial ecosystems, each Plan integrates these agro-ecological areas into a matrix also made up of protected natural spaces. Both are interrelated through ecological corridors that allow for the permanence and development of biodiversity.
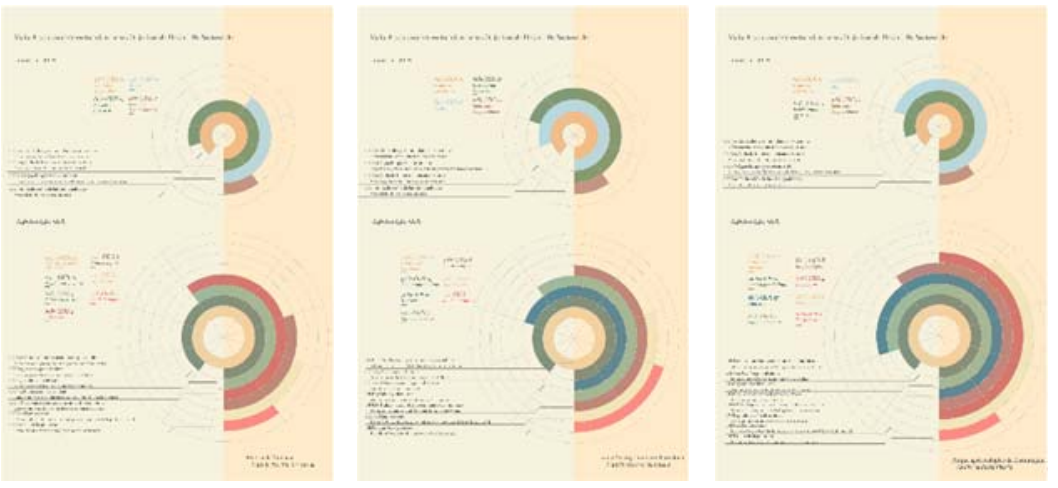

Figure 9. (From left to right $a-b-c)$.

a. Conclusion graph Valencia.

b. Conclusion graph Barcelona.

c. Coclusion graph Vitoria-Gasteiz

Funding: The research received no external funding. Full work available at https://oa.upm.es/67739/

Conflicts of Interest: The author declares no conflict of interest.

\section{References}

1. Mata Olmo, Rafael. Agricultura periurbana y estrategias agroalimentarias en las ciudades y áreas metropolitanas españolas. Viejos problemas, nuevos proyectos. Valencia, PUV, 2018, page 3.

2. Caporal \& Costabeber. 2004. Consulted in Sarandón, Javier Santiago; Flores Claudia Cecilia. Agroecología: El enfoque necesario para una agricultura sustentable: Editorial de la Universidad Nacional de La Plata, EDULP, Buenos Aires, Argentina, 2014; Chapter 2, p. 15.

3. Vía Campesina. World Food Summit, Rome, Italy, 1996.

4. Red de Ciudades por la Agroecología. Planeamiento urbanístico de sistemas alimentarios agroecológicos. Online Webinar. 3, 4 March, 2021. Available at https://short.upm.es/b3jk3. Last access 2021.11.08.

5. VvAa. Generalitat Valenciana, Ayuntamiento de Valencia [ed] Plan de Acción Territorial de la Huerta de Valencia. Valencia, Spain, 2018, 74 pages, pp. 1-38. Available at https://short.upm.es/8s8xl. Last access 2021.11.08.

6. Direcció de Serveis d'Urbanisme de l'Amb. Avance del Plan Director Urbanístico del Área Metropolitana de Barcelona. Barcelona, Spain, February 2019, 255 pages, pp. 214-250. Available at https://short.upm.es/17ubl. Last access 2021.11.08.

7. VvAa. Centro de Estudios Ambientales; Ayuntamiento de Vitoria-Gasteiz [ed]. Aramangelu Parque Agroecológico. VitoriaGasteiz, Spain, April 2019, 51 pages. Available at https://short.upm.es/hniix. Last Access 